\title{
Effect of initial calorie intake via enteral nutrition in critical illness: a meta-analysis of randomised controlled trials
}

Feng Tian ${ }^{1+}$, Xinying Wang ${ }^{1+}$, Xuejin Gao ${ }^{2}$, Xiao Wan ${ }^{1}$, Chao Wu' ${ }^{1}$ Li Zhang ${ }^{1}$, Ning $\mathrm{Li}^{1^{*}}$ and Jieshou $\mathrm{Li}^{1}$

\begin{abstract}
Introduction: Guidelines support the use of enteral nutrition to improve clinical outcomes in critical illness; however, the optimal calorie and protein intake remains unclear. The purpose of this meta-analysis was to quantitatively analyze randomised controlled trials with regard to clinical outcomes related to varying calorie and protein administration in critically ill adult patients.
\end{abstract}

Method: We searched Medline, EMBASE, and Cochrane databases to identify randomised controlled trials that compared the effects of initially different calorie and protein intake in critical illness. The risk ratio (RR) and weighted mean difference with 95\% confidence intervals (Cl) were calculated using random-effects models. The primary endpoint was mortality; secondary endpoints included infection, pneumonia, gastrointestinal intolerance, hospital and intensive care unit lengths of stay, and mechanical ventilation days.

Results: In the eight randomised controlled trials that enrolled 1,895 patients there was no statistical difference between the low-energy and high-energy groups in mortality (RR, $0.90 ; 95 \% \mathrm{Cl}, 0.71$ to $1.15 ; P=0.40$ ), infection (RR, 1.09; $95 \% \mathrm{Cl}, 0.92$ to $1.29 ; P=0.32$ ), or the risk of gastrointestinal intolerance (RR, $0.84 ; 95 \% \mathrm{Cl}, 0.59$ to $1.19 ; P=0.33$ ). In subgroup analysis, the low-energy subgroup, fed 33.3 to $66.6 \%$ of goal energy, showed a lower mortality than the high-energy group (RR, $0.68 ; 95 \% \mathrm{Cl}, 0.51$ to $0.92 ; P=0.01)$. The improvements in mortality and gastrointestinal intolerance were absent when calorie intake was $>66.6 \%$ of goal energy in the low-energy group. High-energy intake combined with high-protein intake reduced the infections (RR, 1.25; $95 \% \mathrm{Cl}, 1.04$ to 1.52; $P=0.02$ ); however, when the daily protein intake was similar in both groups, a high-energy intake did not decrease the infections. No statistical differences were observed in other secondary outcomes.

Conclusion: This meta-analysis indicates that high-energy intake does not improve outcomes and may increase complications in critically ill patients who are not malnourished. Initial moderate nutrient intake (33.3 to 66.6\% of goal energy), compared to high energy, may reduce mortality, and a higher protein intake combined with high energy ( $\geq 0.85 \mathrm{~g} / \mathrm{kg}$ per day) may decrease the infection rate. However, the contribution of energy versus protein intake to outcomes remains unknown.

\section{Introduction}

Enteral nutrition (EN) may not only supply nutrition to patients but also protect intestinal epithelial cells, improve intestinal tight junctions, support intestinal structure and function, and prevent bacterial translocation [1-5]. However, no such beneficial clinical effect of EN

\footnotetext{
* Correspondence: nanjinglining@163.com

${ }^{\dagger}$ Equal contributors

${ }^{1}$ Research Institute of General Surgery, Jinling Hospital, Medical School of Nanjing University, Nanjing, Jiangsu, China

Full list of author information is available at the end of the article
}

has been observed in the first large randomised controlled trial (RCT) comparing isocaloric EN to parenteral nutrition (PN) [5]. Critically ill patients are often in a catabolic state because of the influence of inflammatory cytokines and stress hormones [6]. As a result, patients in the ICU may be at an increased risk of progressive underfeeding, which can result in malnutrition. To avoid malnutrition, the guidelines of several health organisations advocate early EN [7-10]. Unfortunately, critically ill patients may not receive sufficient calories and protein via EN because of gastrointestinal dysmotility, particularly 
delayed gastric emptying [11]. Initial feeding up to the caloric target may lead to high gastric residual volumes, which may increase the risk of aspiration pneumonia and result in longer ICU stays and increased mortality $[5,12]$. However, a limited-energy supplement that is provided because of gastrointestinal intolerance can increase the risk of malnutrition, which may be associated with impaired immune function, weakened or wasted muscles, increased duration of mechanical ventilation, and infectious complications $[13,14]$. Therefore, the initial optimal calorie and protein recommendations for critically ill patients are still unclear.

The European Society for Clinical Nutrition and Metabolism's guidelines suggest that an exogenous energy supply in excess of 20 to $25 \mathrm{kcal} / \mathrm{kg}$ body weight per day may be associated with less favourable outcomes during the acute phase of a critical illness (grade C) [10]. Similarly, the American Society for Parenteral and Enteral Nutrition reported that providing $>50 \%$ to $65 \%$ of goal calories should be attempted as a means of achieving the clinical benefit of EN during the first week of hospitalisation (grade C) [4,7]. However, the Canadian Critical Care Nutrition Clinical Practice Guidelines, because of insufficient data, did not recommend using hypocaloric EN in critically ill patients [9]. Because these three guidelines were published before 2014, when three relevant RCTs were published, the summary of evidence for $\mathrm{EN}$ in critical illness requires updating. Furthermore, the level of evidence of these recent RCTs has not been evaluated.

A cohort study of patients in a respiratory ICU reported that inadequate calorie delivery is associated with higher odds of mortality [15]. Surprisingly, a study comparing hypocaloric and normocaloric nutrition in critically ill patients demonstrated that initial hypocaloric feeding did not affect the hospital or ICU mortality [16]. Conflicting results have even been observed within the same study; the Tight Calorie Control Study showed that near-target energy intake was associated with lower hospital mortality in the per protocol analysis, but increased the duration of the ICU stay and rate of infectious complications in the intention to treat analysis [17]. Therefore, given the heterogeneity of these studies, a meta-analysis of more recent RCTs is needed. The current meta-analysis of eight RCTs aimed to compare initial hypocaloric EN versus hypercaloric EN, with different protein intakes, in critically ill patients.

\section{Methods}

\section{Search strategy}

In this systematic review, we conducted a search of the published literature to identify all relevant clinical trials using the keywords or MeSH headings of 'trophic feeding', 'hypocaloric nutrition', 'permissive underfeeding', 'gradual enteral nutrition', 'standard enteral nutrition', 'intensive enteral nutrition', 'concentrated enteral nutrition', 'hypercaloric nutrition', 'normocaloric nutrition', 'full feeding', 'critical illness', 'critically ill', 'ICU', 'acute lung injury', 'respiratory insufficiency', and 'intensive care' in combination with the Boolean operators AND and OR. Two of the authors (Feng Tian and Xinying Wang) independently performed computerised searches in the MEDLINE, EMBASE, and Cochrane Controlled Trials Register databases. We also searched previous review articles for additional original studies. The final search was conducted on 1 November 2014. No language restrictions were included in the searches. Additionally, abstracts from major scientific meetings were included if they were available for data extraction; authors were approached for additional or missing data, if necessary.

\section{Inclusion criteria}

Two investigators (Feng Tian and Xuejin Gao) independently reviewed all original studies to determine inclusion or exclusion; in the case of disagreement, a third author was consulted. Original studies were selected for inclusion if they met the following criteria: 1) the research design was an RCT or randomized trial or study; 2) the population comprised critically ill adult patients admitted to the ICU (>16 years old); 3 ) the intervention of the study was designed such that the two groups received significantly different calorie intakes by EN; and 4) the clinical outcome of overall mortality of critically ill patients was reported.

\section{Exclusion criteria}

Studies were excluded if they met either of the following criteria: 1) the target calorie supply was different between the two groups; and 2) EN was administered for $<2$ days.

\section{Data extraction}

Two authors (Feng Tian and Xuejin Gao) independently extracted the following variables where they were published and available: demographics, sample size, critical illness severity, amount of daily calorie and protein intake, body mass index (BMI), intervention provided in both groups, and clinical outcomes.

\section{Assessment of quality and risk of bias}

The same two authors independently assessed the study quality and risk of bias using the methods detailed in the Cochrane Handbook for Systematic Reviews of Interventions [18]. Disagreements were resolved in pairs of authors by consensus. The six quality criteria were random sequence generation, allocation concealment, blinding of participants and personnel, blinding of outcome assessment, incomplete outcome data, and selective reporting. 


\section{Statistical analysis}

The primary outcome of this meta-analysis was overall mortality. Hospital mortality in all studies was combined. If hospital mortality was not reported, 60- or 90-day or ICU mortality was used instead. Secondary outcomes included infections (bacteraemia or sepsis was used if the number of infection cases was not reported), pneumonia (ventilator-associated pneumonia and infectious pneumonia), length of stay (LOS) in both hospital (LOS-HOS) and ICU (ICU LOS), and mechanical ventilation days (MVD); these were also pooled for all studies. Despite differences in the definition of gastrointestinal intolerance (high residual gastric volume, regurgitation, vomiting, noninfectious diarrhoea, or abdominal distension), we combined the outcomes where diarrhoea was reported.

The risk ratio (RR) and associated 95\% confidence interval (CI) were used to summarize binary outcomes including mortality, infections, and pneumonia. The overall weighted mean difference (WMD) with 95\% CI was estimated for LOS and MVD. A more conservative random-effects model was used in this meta-analysis because of anticipated heterogeneity. Statistical heterogeneity among trials is expressed as the $P$ value (Cochran's Q statistic), where a $P<0.05$ and $\mathrm{I}^{2}$ statistic $>50 \%$ indicated significant heterogeneity. Subgroup analyses were conducted to find the source of heterogeneity, and a test for heterogeneity interaction was performed to determine whether there was a difference in effect sizes between subgroups. The subgroups were chosen based on their suspected influences on the analyses and previous relevant studies. For instance, the varying calorie intake between studies could influence the aggregate results. Therefore, the eight studies were divided into three subgroups according to the percentage of target energy achieved in the low-energy (LE) group ( $<33.3 \%, 33.3$ to $66.6 \%$, and $>66.6 \%)$. The cut-offs of $33.3 \%$ and $66.6 \%$ were based on a previous cohort study and a recent meta-analysis $[19,20]$. The overlap in studies was managed with subgroup analysis. Funnel plots were used to assess possible bias in reporting and publication; forest plots are presented as pooled data with Review Manager, version 5.3 (Copenhagen: The Nordic Cochrane Centre, The Cochrane Collaboration, 2014).

\section{Results}

\section{Results of the literature search and study selection}

Our detailed search strategy is illustrated in the flow diagram in Figure 1, which follows the strategy recommended by the Preferred Reporting Items for Systematic Reviews and Meta-Analyses group. Our initial search of the electronic databases yielded 6,701 articles: 5,128 articles were duplicates; 808 articles did not include adult patients; 494 articles were not RCTs; 79 articles were of PN; 145 articles were not relevant; five articles were not available; six articles were reviews or meta-analyses;

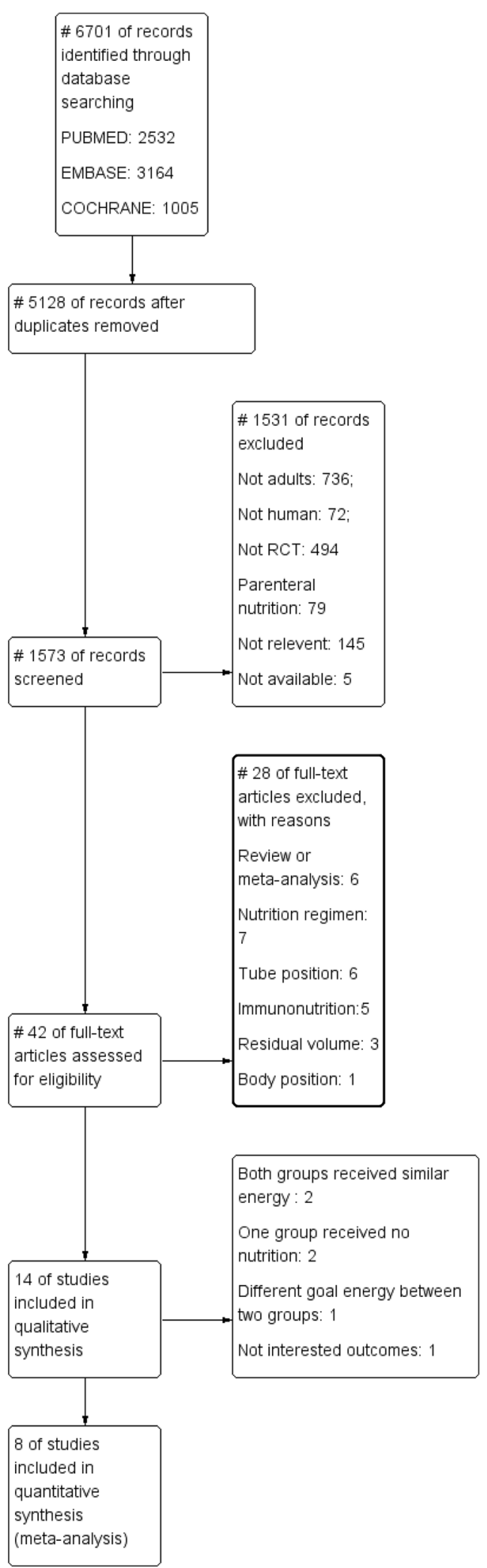

Figure 1 Preferred Reporting Items for Systematic Reviews and Meta-Analyses (PRISMA) statement and accompanying study flow diagram. $\mathrm{RCT}$, randomised controlled trial. 
seven articles included nutrition regimens; six articles were conducted for tube position; five articles were related to immunonutrition; three articles involved residual volume; and one article described body position. Of the 14 potentially relevant articles that were selected for further assessment, six were excluded: two studies reported that both groups were similar, two studies did not administer EN to the LE group, one reported different goal energy levels between the two groups, and one study reported blood glucose and albumin as outcomes, rather than mortality. Thus, eight studies published between 1999 and 2014 fulfilled the inclusion criteria; as a result, 1,895 patients were included in this meta-analysis, of which 951 were in the LE group and 944 were in the high-energy (HE) group [21-28].

\section{Risk of bias in included studies}

Randomisation methods were reported in all eight studies. Allocation concealment was used in six trials using sealed envelopes [21-26], and, although one study did not state allocation concealment, we agreed that this study's allocation method was low risk for our purposes because it used a web-based randomization system [27]. Because of different nutrition doses and titration needs for tolerance and gastric residuals, only two studies used a double-blind design [25,28]. Protocol violations after randomisation occurred in four studies [21,23,25,27]. The assessment for risk of bias in each study is shown in Figure 2. When more than four studies were included, funnel plots were used to assess possible reporting or publication bias (Figures 3, 4 and 5). Figures 3 and 5 show the approximate symmetry of the funnel plots for mortality and pneumonia. Figure 4 shows the asymmetry of the funnel plots for infection; in light of this, we performed a sensitivity analysis to evaluate the robustness of the pooled outcome.

\section{Characteristics of the included studies}

The basic characteristics of patients in the included studies are shown in Tables 1 and 2. The mean age of patients was $>50$ years, except in one study whose patients were $<35$ years of age [28]. The intervention duration in five studies was 5 to 7 days [21,24,26-28] and $>10$ days in three studies $[22,23,25]$. The Acute Physiology and Chronic Health Evaluation (APACHE) II scores in four studies were $>20[21,22,25,26]$ and $<20$ in two studies $[23,28]$. One study used the Simplified Acute Physiology Score [24], and another study used APACHE III scores [27]. The mean BMI of patients in seven studies was $>25 \mathrm{~kg} / \mathrm{m}^{2}$ [21-27]; one study did not report BMI [28].

The mean daily delivered caloric and protein levels differed among studies. In the LE group, the mean daily percentage of target calories in two studies was $<33.3 \%$; in four studies, it was between $33.3 \%$ and $66.6 \%$; and in

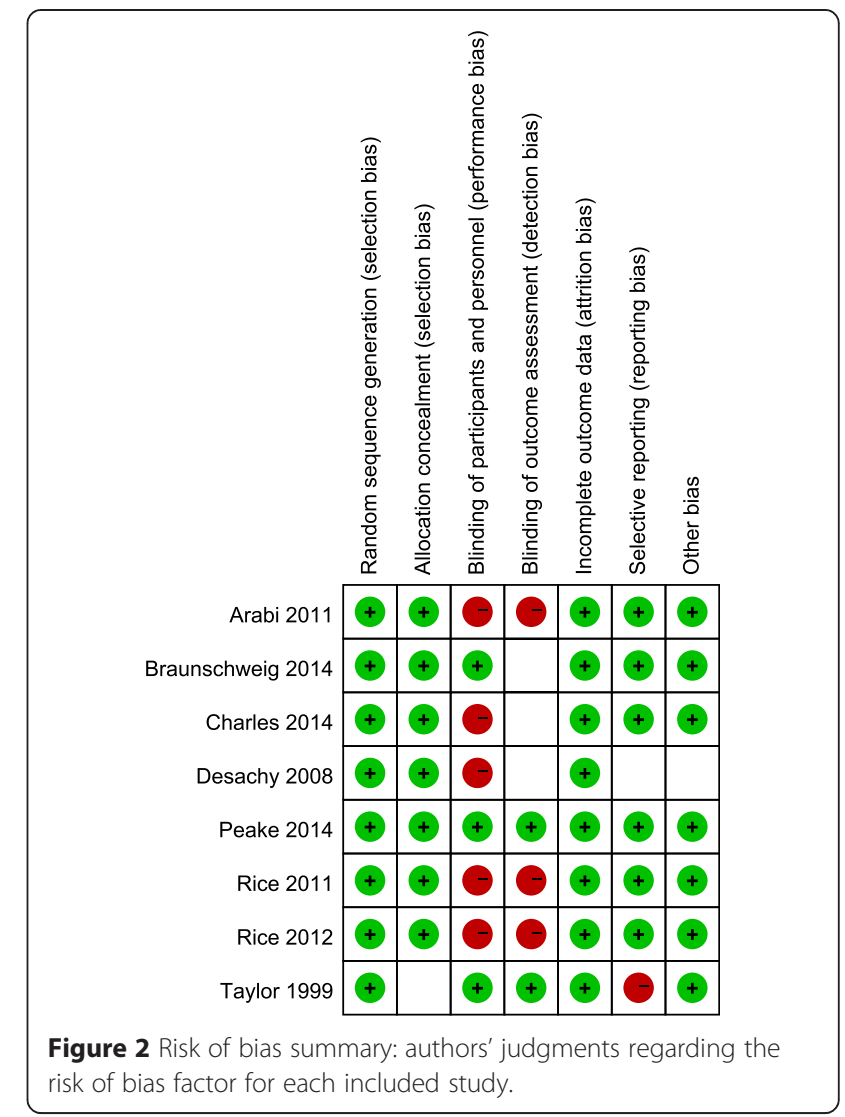

two studies, it was $>66.6 \%$. In the HE group, the percentage of target calories for patients was $>70 \%$ in seven studies and $>90 \%$ in two studies, but it was $59.2 \%$ in one study. Although the caloric intake was $59.2 \%$ for the HE group in the study by Taylor and colleagues [28], the mean target calorie intake was $35 \mathrm{kcal} / \mathrm{kg}$ per day. Therefore, the actual energy intake in the HE group was $20.72 \mathrm{kcal} / \mathrm{kg}$ per day (in the LE group it was $12.88 \mathrm{kcal} / \mathrm{kg}$ per day), which was similar to the caloric intake of the HE group in the other studies. Among the six studies $[21-23,25,26,28]$ that reported daily protein intake levels, the protein levels were different between the HE and LE groups in three studies [22,26,28]. In one study, the protein intake was not reported clearly; however, based on the author's reply that the use of different enteral formulas led to different protein amounts, the different levels of protein intake for the two groups could be estimated [27]. In the studies in the different-protein subgroup, the daily protein intake was $\geq 0.85 \mathrm{~g} / \mathrm{kg}$ per day in each $\mathrm{HE}$ group and $\leq 0.68 \mathrm{~g} / \mathrm{kg}$ per day in each LE group, when adjusted by ideal body weight.

\section{Meta-analysis of primary outcomes}

The primary meta-analysis included all eight studies $(1,895$ participants) and revealed that mortality was not significantly different for patients in the LE group compared 


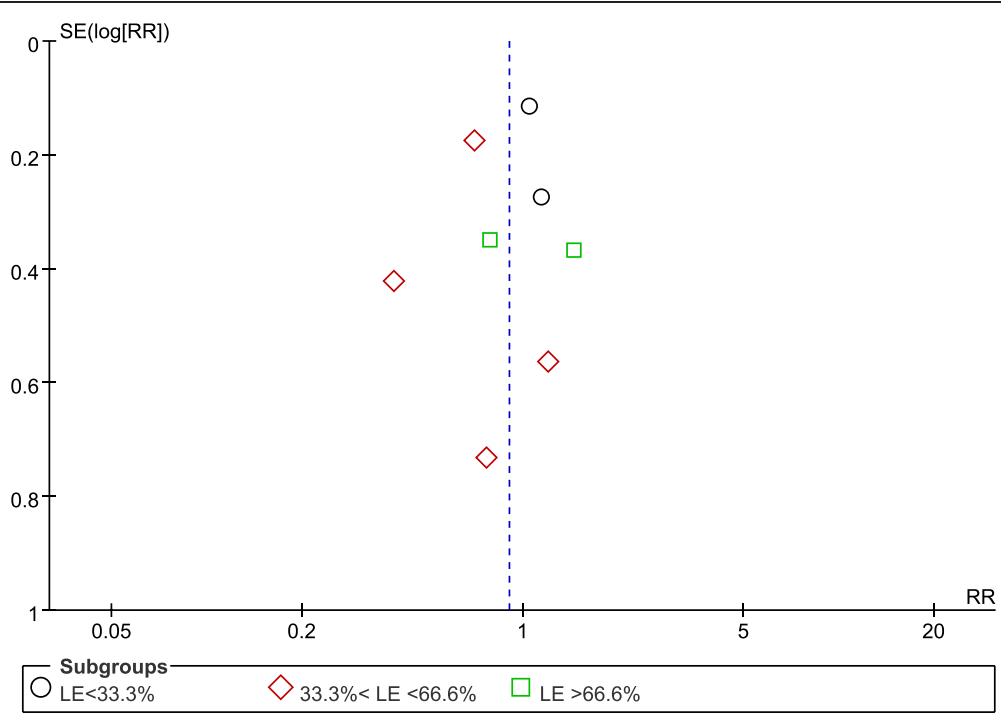

Figure 3 Funnel plots showing the impact of initial low energy intake on mortality. LE, low-energy; RR, risk ratio; SE, standard error.

with the HE group (RR, 0.90; 95\% CI, 0.71 to 1.15; $P=0.40 ; \mathrm{I}^{2}=31 \% ; P=0.18$ ). Subgroup analysis was performed according to the percentage of the goal energy achieved and showed that mortality was significantly different among the three subgroups. Compared with the HE group, mortality was significantly lower in the LE group (fed between $33.3 \%$ and $66.6 \%$ of the goal energy in the LE group; RR, $0.68 ; 95 \% \mathrm{CI}, 0.51$ to $0.92 ; P=0.01 ; \mathrm{I}^{2}=0 \%$; $P=0.43$ ). In contrast, compared with the HE group, mortality was not different in the LE subgroup that was fed $<33.3 \%$ (RR, $1.06 ; 95 \%$ CI, 0.86 to $1.31 ; P=0.57$; $\left.\mathrm{I}^{2}=0 \% ; P=0.77\right)$ or $>66.6 \%$ of the goal energy $(\mathrm{RR}, 1.06$; 95\% CI, 0.58 to $1.93 ; P=0.86 ; \mathrm{I}^{2}=31 \% ; \quad P=0.23$ ). There was significant heterogeneity among the subgroups $\left(\mathrm{I}^{2}=65.7 \% ; P=0.05\right)$ (Figure 6). Subgroup analysis was also performed based on the differences in daily protein intake between the two groups (studies with different protein levels were in one subgroup and studies with the same protein levels were in another subgroup) and showed that mortality was not different between the LE and HE groups in the different or same protein subgroup $\left(\mathrm{I}^{2}=0 \% ; P=0.87\right)$ (see Additional file 1$)$.

\section{Meta-analysis of secondary outcomes Infectious complications}

Six of the eight studies reported infections; these studies included 1,683 patients [21-23,26-28]. The meta-analysis showed no significant difference in infectious complications between the LE and HE groups (RR, 1.09; 95\% CI, 0.92 to 1.29; $\left.P=0.32 ; \mathrm{I}^{2}=31 \% ; P=0.20\right)$.

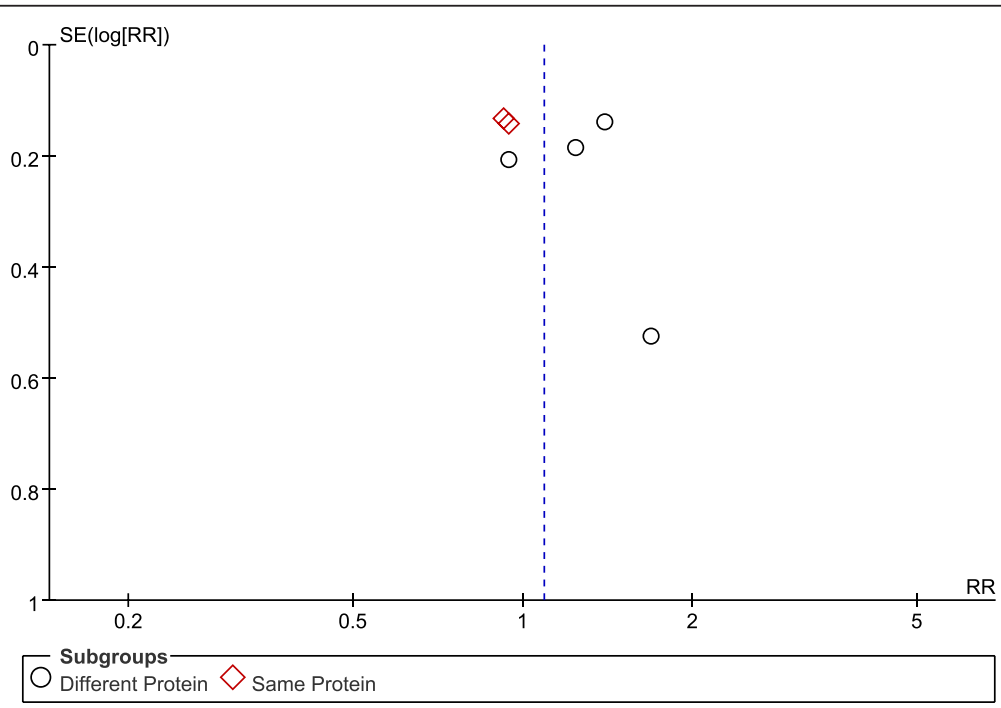

Figure 4 Funnel plots showing the impact of initial low energy intake on infections. RR, risk ratio; SE, standard error. 


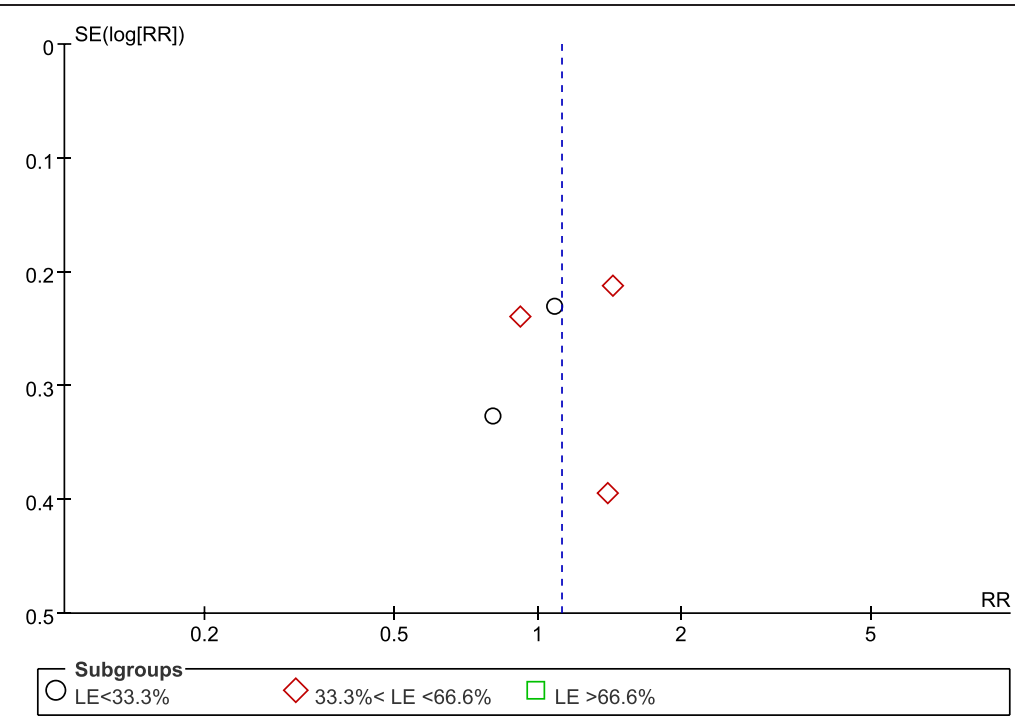

Figure 5 Funnel plots showing the impact of initial low energy intake on pneumonia. LE, low-energy; RR, risk ratio; SE, standard error.

Table 1 Characteristics of the enrolled studies

\begin{tabular}{|c|c|c|c|c|c|c|c|}
\hline \multirow[t]{2}{*}{ Study } & \multicolumn{2}{|c|}{ No. randomized } & \multirow[t]{2}{*}{ Characteristics of patients } & \multicolumn{2}{|l|}{ BMI (SD) } & \multicolumn{2}{|c|}{ Mean APACHE II score (SD) } \\
\hline & $\overline{\mathrm{LE}}$ & $\mathrm{HE}$ & & $\overline{\mathrm{LE}}$ & $\mathrm{HE}$ & $\overline{\mathrm{LE}}$ & $\mathrm{HE}$ \\
\hline \multirow[t]{2}{*}{ Arabi et al. [21] } & 120 & 120 & $>18$ years old & $28.5(7.4)$ & $28.5(8.4)$ & $25.2(7.5)$ & $25.3(8.2)$ \\
\hline & & & ICU $>48$ hours & & & & \\
\hline \multirow[t]{3}{*}{ Braunschweig et al. [22] } & 38 & 40 & $>18$ years old & $30.1(8.9)$ & $29.8(9.3)$ & $27.7(7.9)$ & $23.4(9.3)$ \\
\hline & & & Medical or surgical ICU & & & & \\
\hline & & & ALI $<24$ hours & & & & \\
\hline \multirow[t]{3}{*}{ Charles et al. [23] } & 41 & 42 & $>18$ years old & $32.9(2.0)$ & $28.1(0.9)$ & $16.6(0.9)$ & $17.3(0.8)$ \\
\hline & & & Artificial nutrition $>48$ hours & & & & \\
\hline & & & ICU $>48$ hours & & & & \\
\hline \multirow[t]{3}{*}{ Desachy et al. [24] } & 50 & 50 & $>18$ years old & $27(5)$ & $25(3)$ & $40(11)^{1}$ & $42(17)^{1}$ \\
\hline & & & Medical or surgical ICU & & & & \\
\hline & & & Mechanical ventilation $>72$ hours & & & & \\
\hline \multirow[t]{3}{*}{ Peake et al. [25] } & 55 & 57 & $\geq 18$ years old & $26.2(6.4)$ & $27.8(7.9)$ & $22(8.9)$ & $23(9.1)$ \\
\hline & & & Enteral nutrition $\geq 2$ days & & & & \\
\hline & & & Mechanical ventilation & & & & \\
\hline \multirow[t]{2}{*}{ Rice et al. [26] } & 98 & 102 & ICU admission & $29.2(10.2)$ & $28.2(9.4)$ & $26.9(8.1)$ & $26.9(6.6)$ \\
\hline & & & Mechanical ventilation $>72$ hours & & & & \\
\hline \multirow[t]{3}{*}{ Rice et al. [27] } & 508 & 492 & ICU admission & $29.9(7.8)$ & $30.4(8.2)$ & $92(28)^{2}$ & $90(27)^{2}$ \\
\hline & & & ALI $<48$ hours & & & & \\
\hline & & & Mechanical ventilation $>72$ hours & & & & \\
\hline \multirow[t]{2}{*}{ Taylor et al. [28] } & 41 & 41 & Head injury necessitating mechanical ventilation & N/A & N/A & $14^{3}$ & $14^{3}$ \\
\hline & & & Glasgow Coma Scale $>3$ & & & & \\
\hline
\end{tabular}


Table 2 Nutritional targets and interventions

\begin{tabular}{|c|c|c|c|c|c|c|c|}
\hline \multirow[t]{2}{*}{ Study } & \multirow{2}{*}{$\begin{array}{l}\text { Duration } \\
\text { of study } \\
\text { (days) }\end{array}$} & \multicolumn{2}{|c|}{ Daily target calorie supply (Kcal/kg) } & \multicolumn{2}{|c|}{$\begin{array}{l}\text { Mean daily percentage of caloric } \\
\text { goal (\%) }\end{array}$} & \multicolumn{2}{|c|}{ Mean daily protein intake $(\mathrm{g} / \mathrm{kg}$} \\
\hline & & LE & HE & LE & HE & LE & $\mathrm{HE}$ \\
\hline Arabi et al. [21] & 7 & $N / A^{1}$ & $\mathrm{~N} / \mathrm{A}^{1}$ & 59.0 & 71.4 & $65.2 \%^{2}$ & $63.7 \%^{2}$ \\
\hline Braunschweig et al. [22] & 20 & $25-30$ & $25-30$ & 55.4 & 84.7 & 0.68 & 0.95 \\
\hline Charles et al. [23] & $10-12$ & $25-30$ & $25-30$ & 40.5 & 73 & 1.1 & 1.1 \\
\hline Desachy et al. [24] & 5 & 25 & 25 & 76 & 95 & N/A & N/A \\
\hline Peake et al. [25] & 10 & $25-30$ & $25-30$ & 72 & 102 & 1.05 & 1.02 \\
\hline Rice et al. [26] & 7 & $25-30$ & $25-30$ & 15 & 74.8 & 0.17 & 0.85 \\
\hline Rice et al. [27] & 6 & $25-30$ & $25-30$ & 25 & 80 & N/A & N/A \\
\hline Taylor et al. [28] & 7 & 35 & 35 & 36.8 & 59.2 & 0.57 & 1.03 \\
\hline
\end{tabular}

${ }^{1}$ The caloric requirement was estimated using the Harris-Benedict equation and adjusted for stress factors. ${ }^{2}$ The percentage of protein requirement was calculated on the basis of patient condition and underlying diseases. HE, high-energy; LE, low-energy; N/A, not available.

Subgroup analysis was performed based on daily protein intake differences between the two groups. Relatively higher daily protein and calorie intake decreased infection in the different protein intake subgroups (RR, 1.25; $95 \% \mathrm{CI}, 1.04$ to $\left.1.52 ; P=0.02 ; \mathrm{I}^{2}=0 \% ; P=0.41\right)$. Interestingly, when the daily protein intake was similar, infectious complications were not different between the LE and HE groups (RR, 0.94; $95 \% \mathrm{CI}, 0.77$ to $1.13 ; P=0.50 ; \mathrm{I}^{2}=0 \%$;
$P=0.92)$. There was significant heterogeneity among the subgroups $\left(\mathrm{I}^{2}=77.8 \% ; P=0.03\right)$ (Figure 7 ).

\section{Pneumonia}

Five of the eight studies reported infections; these studies included 1,605 patients [21,23,26-28]. Pneumonia was not significantly different between the groups (RR, 1.12; $95 \% \mathrm{CI}, 0.89$ to $1.41 ; P=0.33 ; \mathrm{I}^{2}=0 \% ; P=0.49$ ).

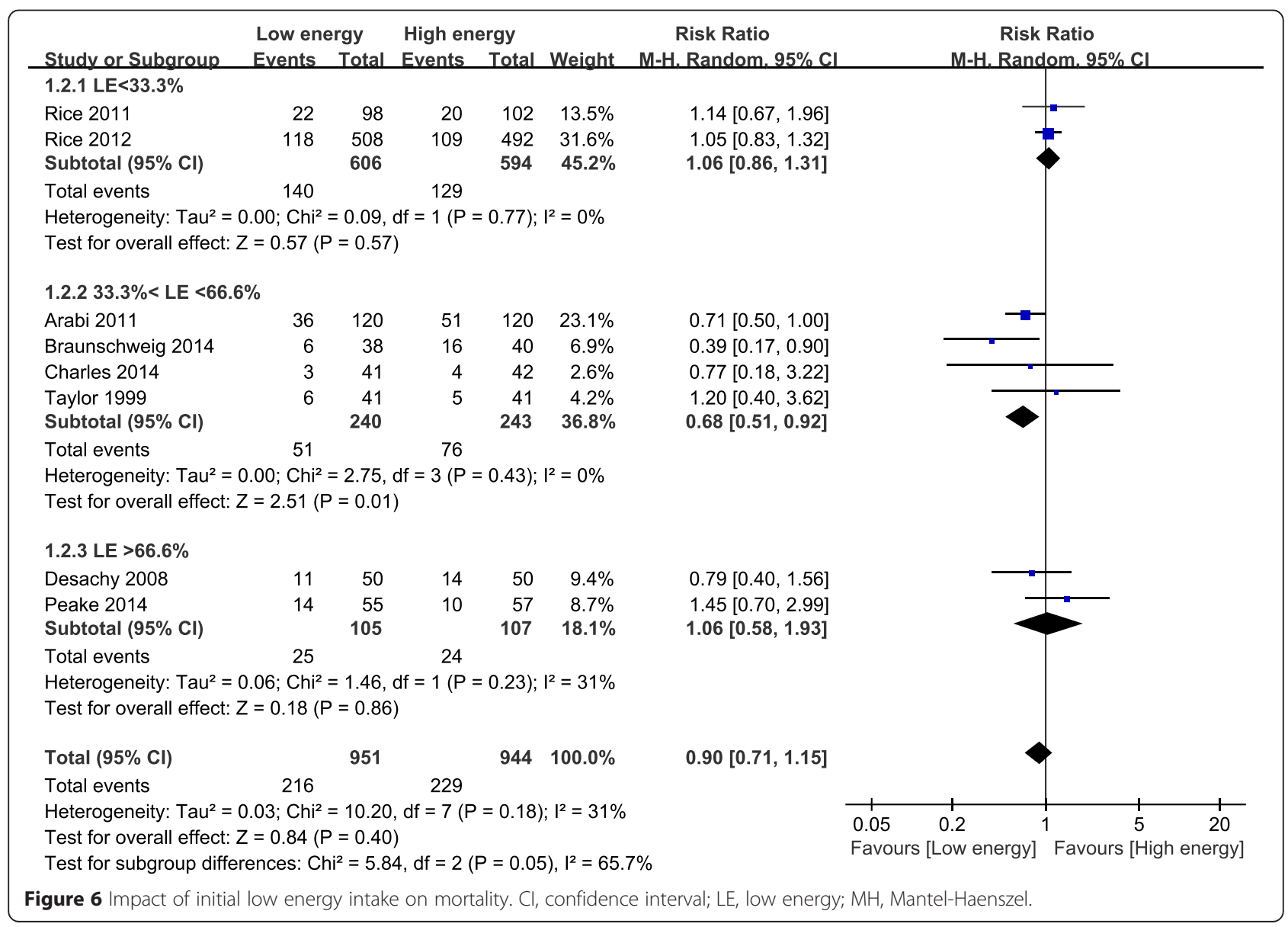




\begin{tabular}{|c|c|c|c|c|c|c|c|c|c|}
\hline Study or Subgroup & \multicolumn{2}{|c|}{ Low energy } & \multicolumn{2}{|c|}{ High energy } & Weight & $\begin{array}{c}\text { Risk Ratio } \\
\text { M-H. Random. } 95 \% \mathrm{Cl}\end{array}$ & \multicolumn{3}{|c|}{$\begin{array}{c}\text { Risk Ratio } \\
\text { M-H. Random. } 95 \% \mathrm{Cl} \\
\end{array}$} \\
\hline \multicolumn{10}{|l|}{ 2.1.1 Different Protein } \\
\hline Braunschweig 2014 & 8 & 38 & 5 & 40 & $2.6 \%$ & $1.68[0.60,4.70]$ & & & \\
\hline Rice 2011 & 30 & 98 & 33 & 102 & $13.1 \%$ & $0.95[0.63,1.42]$ & & & \\
\hline Rice 2012 & 59 & 508 & 46 & 492 & $15.5 \%$ & $1.24[0.86,1.79]$ & & & \\
\hline Taylor 1999 & 35 & 41 & 25 & 41 & $22.4 \%$ & $1.40[1.06,1.84]$ & & & \\
\hline Subtotal $(95 \% \mathrm{Cl})$ & & 685 & & 675 & $53.7 \%$ & $1.25[1.04,1.52]$ & & & \\
\hline Total events & 132 & & 109 & & & & & & \\
\hline \multicolumn{10}{|c|}{ Heterogeneity: $\mathrm{Tau}^{2}=0.00 ; \mathrm{Chi}^{2}=2.88, \mathrm{df}=3(\mathrm{P}=0.41) ; \mathrm{I}^{2}=0 \%$} \\
\hline \multicolumn{10}{|c|}{ Test for overall effect: $Z=2.32(P=0.02)$} \\
\hline \multicolumn{10}{|l|}{ 2.1.2 Same Protein } \\
\hline Arabi 2011 & 53 & 120 & 56 & 120 & $22.3 \%$ & $0.95[0.72,1.25]$ & & & \\
\hline Charles 2014 & 29 & 41 & 32 & 42 & $24.1 \%$ & $0.93[0.72,1.20]$ & & & \\
\hline Subtotal $(95 \% \mathrm{Cl})$ & & 161 & & 162 & $46.3 \%$ & $0.94[0.77,1.13]$ & & & \\
\hline Total events & 82 & & 88 & & & & & & \\
\hline \multirow{2}{*}{\multicolumn{10}{|c|}{$\begin{array}{l}\text { Heterogeneity: } \text { Tau }^{2}=0.00 ; \mathrm{Chi}^{2}=0.01, \mathrm{df}=1(\mathrm{P}=0.92) ; \mathrm{I}^{2}=0 \% \\
\text { Test for overall effect: } Z=0.68(\mathrm{P}=0.50)\end{array}$}} \\
\hline & & & & & & & & & \\
\hline Total $(95 \% \mathrm{Cl})$ & & 846 & & 837 & $100.0 \%$ & $1.09[0.92,1.29]$ & & & \\
\hline Total events & 214 & & 197 & & & & & & \\
\hline \multicolumn{7}{|c|}{ Heterogeneity: $\mathrm{Tau}^{2}=0.01 ; \mathrm{Chi}^{2}=7.27, \mathrm{df}=5(P=0.20) ;\left.\right|^{2}=31 \%$} & $0.2 \quad 0.5$ & 2 & 5 \\
\hline \multicolumn{7}{|c|}{ Test for overall effect: $Z=0.99(P=0.32)$} & Favours [Low energy] & Favours [Hig & nergy] \\
\hline \multicolumn{10}{|c|}{ Test for subgroup differences: $\mathrm{Chi}^{2}=4.50, \mathrm{df}=1(\mathrm{P}=0.03), \mathrm{I}^{2}=77.8 \%$} \\
\hline
\end{tabular}

Subgroup analysis showed that pneumonia was not affected by the percentage of the goal energy achieved $\left(\mathrm{I}^{2}=0 \% ; P=0.39\right)$ or the daily protein intake $\left(\mathrm{I}^{2}=0 \%\right.$; $P=0.67$ ) (Figure 8).

\section{Gastrointestinal intolerance}

Three of the eight studies reported gastrointestinal intolerance; these studies included 452 patients [21,24,25]. Patients initially receiving LE did not decrease the risk of gastrointestinal intolerance compared with those initially receiving $\mathrm{HE}(\mathrm{RR}, 0.84 ; 95 \% \mathrm{CI}, 0.59$ to 1.19 ; $\left.P=0.33 ; \mathrm{I}^{2}=20 \% ; P=0.29\right)$. Subgroup analysis showed that gastrointestinal intolerance in the LE group that was fed $33.3 \%$ to $66.6 \%$ of the goal energy was significantly lower than that in the HE group (RR, 0.65; 95\% $\mathrm{CI}, 0.43$ to $0.99 ; P=0.05)$. However, this advantage was not obvious in the LE group that was fed $>66.6 \%$ of the goal energy (RR, $1.06 ; 95 \% \mathrm{CI}, 0.68$ to $1.64 ; P=0.80$; $\left.\mathrm{I}^{2}=0 \% ; P=0.86\right)$, compared with the HE group fed $>95 \%$ of the goal energy (Figure 9 ).

\section{Length of intensive care unit stay}

The data from four studies with 501 patients showed no statistically significant differences for ICU LOS between the two groups (WMD, $-0.50 ; 95 \% \mathrm{CI},-2.99$ to $1.99 ; P=0.69 ; \mathrm{I}^{2}=22 \% ; P=0.28$ ) [21-24]. Subgroup analysis indicated that the LOS-HOS was not affected by the percentage of the goal energy achieved $\left(\mathrm{I}^{2}=0 \%\right.$; $P=0.91)$ or daily protein intake $\left(\mathrm{I}^{2}=0 \% ; P=0.97\right)$ (see Additional file 2).

\section{Length of hospital stay}

On the basis of the meta-analysis of four studies with 501 participants, the LOS-HOS was not significantly different between the groups (WMD, -1.64; 95\% CI, -7.35 to $4.07 ; P=0.57 ; \mathrm{I}^{2}=0 \% ; P=0.60$ ) [21-24]. Subgroup analysis indicated that LOS-HOS was not affected by the percentage of the goal energy achieved $\left(\mathrm{I}^{2}=0 \% ; P=0.80\right)$ or daily protein intake $\left(\mathrm{I}^{2}=0 \% ; P=0.39\right.$ ) (see Additional file 3).

\section{Mechanical ventilation days}

For the two studies of 440 patients that provided data on MVD, our meta-analysis showed no difference between the LE and HE groups (WMD, $-1.04 ; 95 \% \mathrm{CI},-3.29$ to $\left.1.20 ; P=0.36 ; \mathrm{I}^{2}=46 \% ; P=0.17\right)[21,26]$ (Figure 10).

\section{Discussion}

In this meta-analysis of eight RCTs of critically ill adult patients, there were no statistically significant differences in mortality, infections, pneumonia, ICU LOS, LOS-HOS, MVD or gastrointestinal intolerance between the LE and HE groups. In the subgroup analysis of the LE group that was fed between $33.3 \%$ and $66.6 \%$ of the goal energy, mortality was significantly lower than in the HE group. Nevertheless, when the LE group was fed $<33.3 \%$ or $>66.6 \%$ of the goal energy, this advantage in mortality was not present, nor was the decreased risk for gastrointestinal intolerance, compared with the HE group. Furthermore, when the HE group received more protein than the LE group, infections decreased. This advantage was no longer 


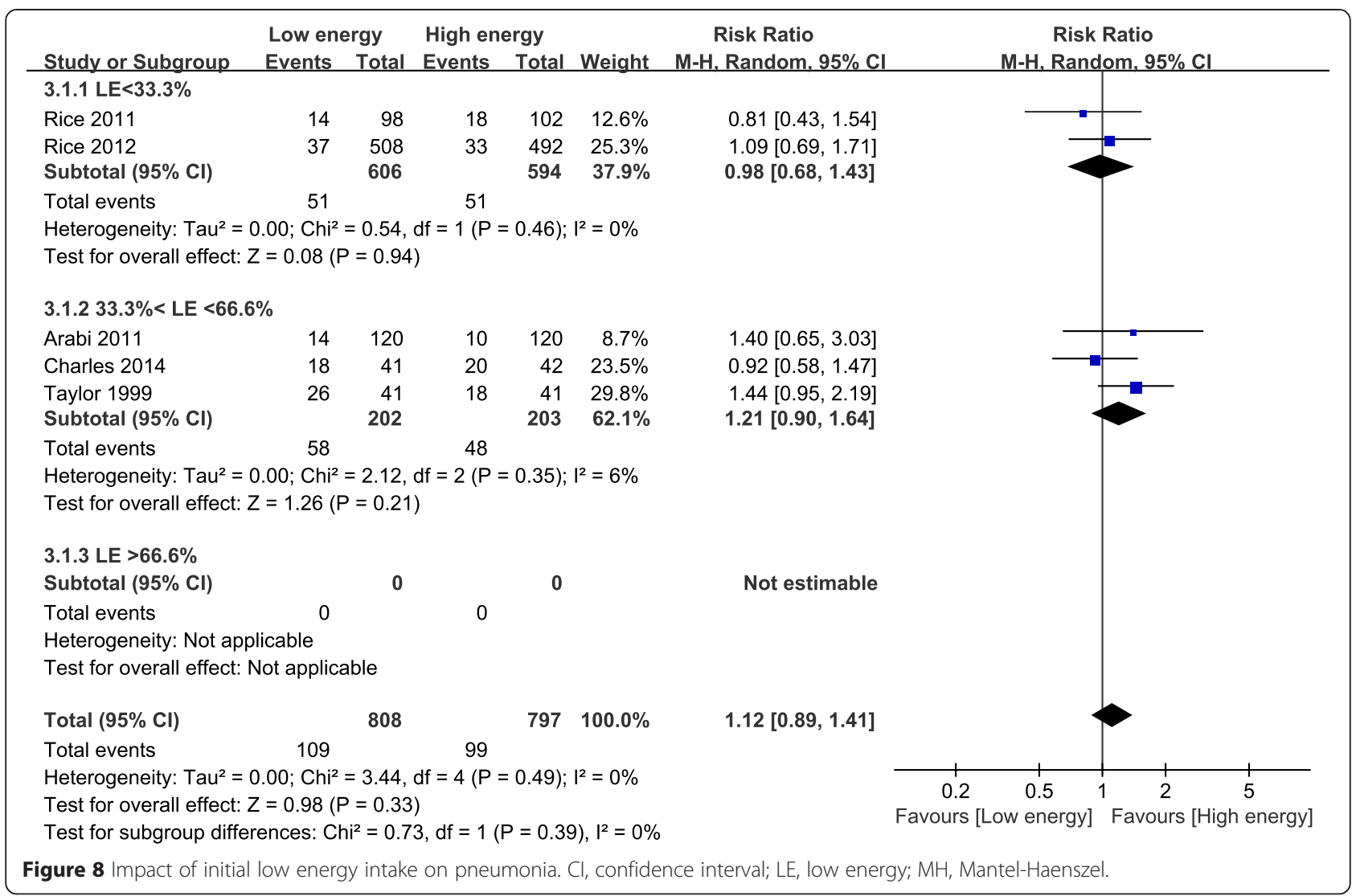

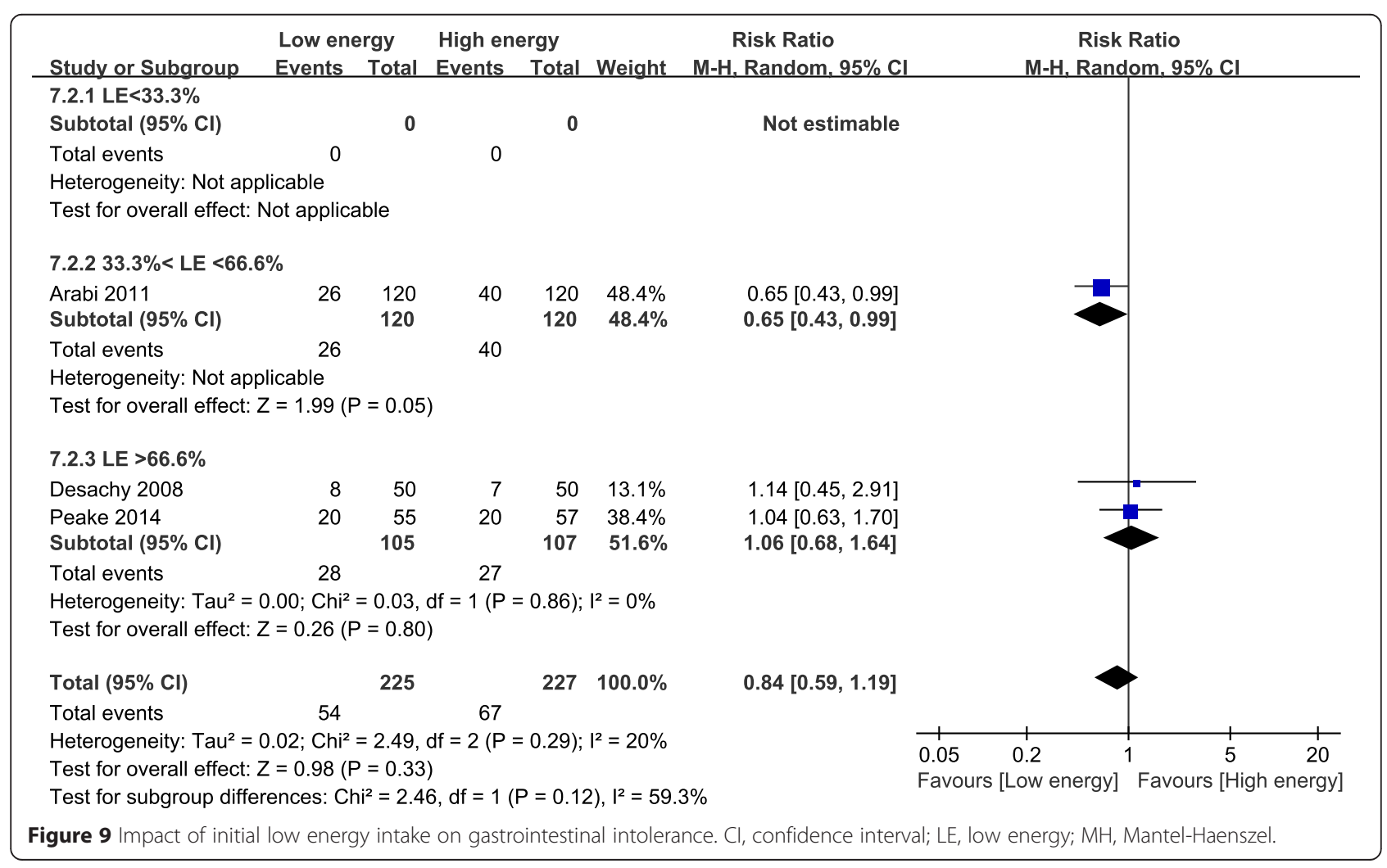




\begin{tabular}{|c|c|c|c|c|c|c|c|c|c|}
\hline \multirow[b]{2}{*}{ Study or Subgroup } & \multicolumn{3}{|c|}{ Experimental } & \multicolumn{3}{|c|}{ Control } & \multirow[b]{2}{*}{ Weight } & \multirow{2}{*}{$\begin{array}{l}\text { Mean Difference } \\
\text { IV. Random, } 95 \% \mathrm{Cl}\end{array}$} & \multirow{2}{*}{$\begin{array}{c}\text { Mean Difference } \\
\text { IV. Random, } 95 \% \mathrm{Cl}\end{array}$} \\
\hline & Mean & SD & Total & Mean & SD & Total & & & \\
\hline \multicolumn{10}{|l|}{ 6.4.1 LE<33.3\% } \\
\hline $\begin{array}{l}\text { Rice } 2011 \\
\text { Subtotal }(95 \% \mathrm{Cl})\end{array}$ & 5.5 & 5.4 & $\begin{array}{l}98 \\
98\end{array}$ & 5.7 & 6.4 & $\begin{array}{l}102 \\
102\end{array}$ & $\begin{array}{l}64.8 \% \\
64.8 \%\end{array}$ & $\begin{array}{l}-0.20[-1.84,1.44] \\
-0.20[-1.84,1.44]\end{array}$ & \\
\hline \multicolumn{10}{|c|}{ Heterogeneity: Not applicable } \\
\hline \multicolumn{10}{|c|}{$6.4 .233 .3 \%<$ LE $<66.6 \%$} \\
\hline $\begin{array}{l}\text { Arabi } 2011 \\
\text { Subtotal }(95 \% \mathrm{Cl})\end{array}$ & 10.6 & 7.6 & $\begin{array}{l}120 \\
120\end{array}$ & 13.2 & 15.2 & $\begin{array}{l}120 \\
120\end{array}$ & $\begin{array}{l}35.2 \% \\
35.2 \%\end{array}$ & $\begin{array}{l}-2.60[-5.64,0.44] \\
-2.60[-5.64,0.44]\end{array}$ & \\
\hline \multicolumn{2}{|c|}{ Test for overall effect: $Z=1.68(P=0.09)$} & & & & & & & & \\
\hline \multicolumn{10}{|l|}{6.4 .3 LE $>66.6 \%$} \\
\hline $\begin{array}{l}\text { Peake } 2014 \\
\text { Subtotal }(95 \% \mathrm{Cl})\end{array}$ & 0 & 0 & $\begin{array}{l}0 \\
0\end{array}$ & 0 & 0 & $\begin{array}{l}0 \\
0\end{array}$ & & $\begin{array}{r}\text { Not estimable } \\
\text { Not estimable }\end{array}$ & \\
\hline \multicolumn{10}{|c|}{ Heterogeneity: Not applicable } \\
\hline Total $(95 \% \mathrm{Cl})$ & & & 218 & & & 222 & $100.0 \%$ & $-1.04[-3.29,1.20]$ & \\
\hline $\begin{array}{l}\text { Heterogeneity: } \mathrm{Tau}^{2}= \\
\text { Test for overall effect: } \\
\text { Test for subgroup diff }\end{array}$ & $\begin{array}{l}1.33 ; \mathrm{Ch} \\
\mathrm{Z}=0.91 \\
\text { rences: }\end{array}$ & $\begin{array}{l}2=1 \\
(P=0 \\
h^{2}{ }^{2}=\end{array}$ & $\begin{array}{l}5, \mathrm{df}= \\
36) \\
1.85, \mathrm{~d}\end{array}$ & $\begin{array}{l}1(P= \\
f=1(P\end{array}$ & $\begin{array}{l}0.17) ; \\
=0.17\end{array}$ & $I^{2}=46^{\circ}$ & $\begin{array}{l}\% \\
46.1 \%\end{array}$ & & $\begin{array}{ccccc}-4 & -2 & 0 & 2 & 4 \\
\text { Favours [Low energy] } & \text { Favours [High energy] }\end{array}$ \\
\hline
\end{tabular}

present when the patients received similar protein levels; however, these findings should be confirmed with additional studies, given the methodological limitations of the present study as described later in the discussion.

Current guidelines recommend that nutrition should be provided to critically ill adults owing to the risk of malnutrition. In addition, nutrition should be initiated as soon as possible, ideally within 24 to 48 hours of ICU admission $[4,7,9]$. Early EN improves outcomes in critical illness and may be the optimal delivery route in those patients with adequate gastrointestinal tract function, compared with PN [5,7]. However, weak gastrointestinal function limits the effective delivery of EN. For more effective delivery, supplemental parenteral nutrition (SPN) was recently attempted; however, consistent results were not obtained from different trials regarding whether SPN results in harm, and no study showed clear benefit [29]. Therefore, consensus regarding the early use of SPN as a way to supply sufficient energy to patients does not exist [30-32]. Although PN may have resulted in the negative outcomes in these studies, recent RCTs have shown that PN does not harm the critically ill [5]. Owing to the conflicting results, the calorie dose is suspected as important for clinical outcomes in critically ill patients $[5,33,34]$.

Since 2009, several cohort studies have investigated the relationship between calorie intake and clinical outcomes in critical illness. A multicentre cohort study of 2,772 patients in 2009 indicated that increased energy and protein intake might be associated with reduced mortality and MVD [35]. However, another cohort study suggested that reduced caloric intake improves clinical outcomes in critically ill patients [36]. The nutrition regimen in these studies involved EN, PN, and EN with PN. Because the benefits of EN might be counteracted by other nutrition regimens, the present meta-analysis focused on calorie and protein intake using EN alone.

The recent major guidelines on EN in critically ill patients are not supported by our results $[9,10]$, perhaps because those recommendations were based on only two previous RCTs [28,37]. However, more relevant studies, including three related RCTs in the past year, have been reported since the guidelines were published. The recent meta-analysis by Choi and colleagues [20] of four RCTs regarding the relationship between clinical outcomes and EN-administered calories in critically ill adults showed that overall mortality was significantly reduced when underfed patients received $\geq 33.3 \%$ of the standard caloric requirement; however, differences between subgroups of 33.3 to $66.6 \%$ and $>66.6 \%$ standard caloric requirements were not investigated because of the low number of included studies. This is despite the results of a previous cohort study that demonstrated that patients in the middle tertile (33 to $65 \%$ of target energy) were more likely to be discharged from the ICU with spontaneous ventilation than patients in the lowest and highest tertiles [19]. The risk of gastrointestinal intolerance was higher with increased energy supplied by EN; in turn, mortality increased, which might support the benefits of LE [12]. Similarly, in the present meta-analysis, mortality was similar in the LE group who were fed $>66.6 \%$ of the goal energy compared with the HE group.

In addition, we found that decreased infection rates might be attributed to $\mathrm{HE}$ combined with high protein 
intake, which is consistent with previous observational studies that declared that a relatively higher protein intake might improve clinical outcomes [38,39]. Because lower infection rates were observed with daily protein intake $\geq 0.85 \mathrm{~g} / \mathrm{kg}$, compared with $\leq 0.68 \mathrm{~g} / \mathrm{kg}$, daily protein intake $\geq 0.85 \mathrm{~g} / \mathrm{kg}$ might be effective for prevention of infections, despite being lower than recommendations (1.2 to $1.5 \mathrm{~g} / \mathrm{kg}$ per day). Moreover, the finding that infections did not increase mortality is noteworthy. It is possible that mortality could not be determined by infections alone; for example, some infections may not be serious enough to result in death. In the study by Taylor and colleagues, infections were significantly higher in the LE group without any differences in mortality between the LE and HE groups [28]. Similarly, in the study by Braunschweig and colleagues [22], a dramatic increase in mortality was observed in the HE group despite relatively lower infection rates. That was possibly explained by the increased mortality as patients who die in ICU no longer develop infections. Furthermore, infectious outcomes are more vulnerable to bias in these often open-label studies, which might also explain the isolated finding of fewer infectious diagnoses but no effect on clinical outcome. However, in the present study, no specific search was conducted for low versus high protein intake, and related RCTs for LE combined with high protein intake were lacking. Moreover, we were not able to explore other aspects, such as pneumonia or LOS-HOS, because of the limited number of studies and the diverse protein dose among studies. Therefore, we could not provide an optimal range of daily protein intake, but we noted that, as protein intake increased, the infection rate decreased. More studies using similar protocols are required to determine optimal intake levels. In addition, none of the eight included studies showed that patients were administrated the recommended amount of protein, suggesting that protein deficiency might not be appropriately addressed in clinical practice and daily protein deficiency might impact clinical outcomes, such as infections. More concern should be given to protein supply in the critically ill patients in the future.

Although we attempted to reduce bias, the results of the present study should be treated with caution because of certain limitations. First, this meta-analysis included a small number of studies; although we included four studies more than a previous meta-analysis [20], data regarding gastrointestinal intolerance in the subgroup that received $<33.3 \%$ of the goal energy are lacking. Thus, more high-quality studies are needed before a reliable conclusion can be determined. Second, the disease severity reported by the studies differed. The low APACHE II scores in two studies were associated with low mortality, which might have contributed to heterogeneity $[23,28]$. Third, the significant variations in calorie intake in the LE groups might have resulted in significant overlap between studies, potentially affecting the aggregated results. We attempted to overcome this variability and potential overlap through subgroup analysis, but the results should still be treated with caution. Fourth, the data were presented differently between studies; for instance, four studies presented the median MVD rather than mean MVD [22,23,25,27]. Because we did not believe these should be used together in our meta-analysis, only two studies were included in the MVD analysis. For the same reason, only four of eight studies were included in the ICU LOS and LOS-HOS analyses, and only one of the four studies was in the different-protein subgroup, while the other three studies were in the same-protein subgroup. As a result, the ICU LOS and HOS-LOS in the HE with high protein subgroup was only present in the study by Braunschweig and colleagues rather than in the aggregated results of four studies, and the results could not accurately reflect whether HE with high protein influences the LOS. Within the three studies of the sameprotein subgroup, the ICU LOS and LOS-HOS were not different between the HE and LE groups. Therefore, the pooled results could only suggest that no effects were present in the comparison of the HE and LE groups. Fifth, the intervention duration in three studies was longer than in the other five studies; however, the results did not vary significantly by subgroup analysis. Sixth, none of the selected studies, except one, stated that the mean BMI of patients was $>25 \mathrm{~kg} / \mathrm{m}^{2}$, which suggests that our conclusions may not be appropriate for malnourished patients. In addition, although the sensitivity analysis revealed that the overall pooled results were stable, the conclusions for the subgroups were affected; therefore, the results should be interpreted with caution, and additional studies are required.

\section{Conclusions}

In summary, there were no significant differences between the initial LE and HE groups of critically ill adult patients. According to this meta-analysis, initial moderate nutrient intake (33.3\% to $66.6 \%$ of goal energy) as compared to HE may reduce mortality, and a higher protein intake combined with $\mathrm{HE}(\geq 0.85 \mathrm{~g} / \mathrm{kg}$ per day) may decrease the infection rates. However, because of the study limitations, the optimal dose of initial calorie and protein intake is still uncertain, and further largesample RCTs are needed to confirm our conclusions.

\section{Key messages}

- Initial moderately low calorie intake could improve the prognosis of critical illness and excessively low or high calorie intake should be avoided in these patients. 
- A relatively high protein intake might benefit critically ill patients, but the daily administration of protein should not exceed the upper limit of the recommended range.

- The current data are not sufficient to draw conclusions regarding the optimal initial calorie and protein intake to be administered by EN in non-malnourished critically ill adults because of the limited number and heterogeneity of the trials, including the varying calorie and protein intake in the eight included studies.

- More rigorously designed studies using similar protocols are required to determine the optimal levels of calorie and protein intake.

\section{Additional files}

Additional file 1: Impact of initial low energy intake on mortality (subgroup analysis of protein intake). $\mathrm{Cl}$, confidence interval; $\mathrm{MH}$, Mantel-Haenszel.

Additional file 2: Impact of initial low energy intake on length of intensive care unit stay. $\mathrm{Cl}$, confidence interval; IV, inverse variance; $L E$, low energy.

Additional file 3: Impact of initial low energy intake on length of hospital stay. Cl, confidence interval; IV, inverse variance; LE, low energy.

\section{Abbreviations}

APACHE: Acute Physiology and Chronic Health Evaluation; BMI: body mass index; Cl: confidence interval; EN: enteral nutrition; HE: high-energy; ICU LOS: intensive care unit length of stay; LE: low-energy; LOS: length of stay; LOS-HOS: hospital length of stay; MVD: mechanical ventilation days; PN: parenteral nutrition; RCT: randomised controlled trial; RR: risk ratio; SPN: supplemental parenteral nutrition; WMD: weighted mean difference.

\section{Competing interests}

The authors declare that they have no competing interests.

\section{Authors' contributions}

$\mathrm{FT}$, Xinying Wang, NL, and JL were involved with study concept and design. $F T, X G$, Xiao Wan, CW and $L Z$ were involved in data acquisition. $F T, X G$, Xinying Wang, and CW interpreted the data and results of the analyses. FT drafted the manuscript, which was critically revised for intellectual content by NL, Xinying Wang, LZ, and JL. The revised version was modified under the direction of NL. All authors read and approved the final manuscript.

\section{Authors' information}

Xinying Wang, Ning Li and Jieshou Li are specialists of critical disease and clinical nutrition; Jieshou Li is also a member of the Chinese Academy of Engineering. Ning $\mathrm{Li}$ is the former chairman of the China Society of Parenteral and Enteral Nutrition, and Xinying Wang is the vice-chairman of the China Society of Parenteral and Enteral Nutrition. Feng Tian, Xuejin Gao, Xiao Wan, Chao Wu and Li Zhang are the resident doctors of general surgery who are conducting a study of nutrition support in critical illness.

\section{Acknowledgements}

We thank Stephen J Taylor for providing detailed information regarding his studies.

\section{Author details}

${ }^{1}$ Research Institute of General Surgery, Jinling Hospital, Medical School of Nanjing University, Nanjing, Jiangsu, China. ${ }^{2}$ Department of General Surgery, Jinling Hospital, South Medical University, Guangdong, China.

Received: 24 November 2014 Accepted: 30 March 2015

Published online: 20 April 2015

\section{References}

1. Kane TD, Alexander JW, Johannigman JA. The detection of microbial DNA in the blood: a sensitive method for diagnosing bacteremia and/or bacterial translocation in surgical patients. Ann Surg. 1998;227:1-9.

2. MacFie J, Reddy BS, Gatt M, Jain PK, Sowdi R, Mitchell CJ. Bacterial translocation studied in 927 patients over 13 years. Br J Surg. 2006;93:87-93.

3. Alverdy JC, Aoys E, Moss GS. Total parenteral nutrition promotes bacterial translocation from the gut. Surgery. 1988;104:185-90.

4. Martindale RG, McClave SA, Vanek WW, McCarthy M, Roberts P, Taylor B, et al. Guidelines for the provision and assessment of nutrition support therapy in the adult critically ill patient: Society of Critical Care Medicine and American Society for Parenteral and Enteral Nutrition: Executive Summary. Crit Care Med. 2009;37:1757-61.

5. Harvey SE, Parrott F, Harrison DA, Bear DE, Segaran E, Beale R, et al. Trial of the route of early nutritional support in critically ill adults. N Engl J Med. 2014;371:1673-84.

6. Pasini E, Aquilani R, Dioguardi FS, D'Antona G, Gheorghiade M, Taegtmeyer H. Hypercatabolic syndrome: molecular basis and effects of nutritional supplements with amino acids. Am J Cardiol. 2008;101:11E-5.

7. McClave SA, Martindale RG, Vanek W, McGarthy M, Roberts P, Taylor B, et al. Guidelines for the provision and assessment of nutrition support therapy in the adult critically ill patient: Society of Critical Care Medicine (SCCM) and American Society for Parenteral and Enteral Nutrition (ASPEN). JPEN J Parenter Enteral Nutr. 2009;33:277-316.

8. Singer $P$, Berger MM, Van den Berghe $G$, Biolo G, Calder $P$, Forbes A, et al. ESPEN. ESPEN guidelines on parenteral nutrition: intensive care. Clin Nutr. 2009;28:387-400.

9. Dhaliwal R, Cahill N, Lemieux M, Heyland DK. The Canadian critical care nutrition guidelines in 2013: an update on current recommendations and implementation strategies. Nutr Clin Pract. 2014;29:29-43.

10. Kreymann KG, Berger MM, Deutz NE, Hiesmayr M, Jolliet P, Kazandjiev G, et al. ESPEN (European Society for Parenteral and Enteral Nutrition). ESPEN guidelines on enteral nutrition: intensive care. Clin Nutr. 2006;25:210-23.

11. Chapman MJ, Besanko LK, Burgstad CM, Fraser RJ, Bellon M, O'Connor S, et al. Gastric emptying of a liquid nutrient meal in the critically ill: relationship between scintigraphic and carbon breath test measurement. Gut. 2011;60:1336-43.

12. Mentec $H$, Dupont $H$, Bocchetti M, Cani P, Ponche F, Bleichner G. Upper digestive intolerance during enteral nutrition in critically ill patients: frequency, risk factors, and complications. Crit Care Med. 2001;29:1955-61.

13. Dempsey DT, Mullen JL, Buzby GP. The link between nutritional status and clinical outcome: can nutritional intervention modify it? Am J Clin Nutr. 1988;47:352-6.

14. Goiburu ME, Goiburu MM, Bianco H, Díaz JR, Alderete F, Palacios MC, et al. The impact of malnutrition on morbidity, mortality and length of hospital stay in trauma patients. Nutr Hosp. 2006;21:604-10.

15. Singh N, Gupta D, Aggarwal AN, Agarwal R, Jindal SK. An assessment of nutritional support to critically ill patients and its correlation with outcomes in a respiratory intensive care unit. Respir Care. 2009;54:1688-96.

16. Petros S, Horbach M, Seidel F, Weidhase L. Hypocaloric vs normocaloric nutrition in critically ill patients: a prospective randomized pilot trial. JPEN J Parenter Enteral Nutr. 2014. Epub.

17. Singer P, Anbar R, Cohen J, Shapiro H, Shalita-Chesner M, Lev S, et al. The tight calorie control study (TICACOS): a prospective, randomized, controlled pilot study of nutritional support in critically ill patients. Intensive Care Med. 2011;37:601-9.

18. JPT CHH, Green S. Cochrane handbook for systematic reviews of interventions version 5.1. 0 [updated March 2011]. Cochrane Collaboration. 2011.

19. Krishnan JA, Parce PB, Martinez A, Diette GB, Brower RG. Caloric intake in medical ICU patients: consistency of care with guidelines and relationship to clinical outcomes. Chest. 2003;124:297-305.

20. Choi EY, Park DA, Park J. Calorie intake of enteral nutrition and clinical outcomes in acutely critically ill patients: a meta-analysis of randomized controlled trials. JPEN J Parenter Enteral Nutr. 2014.

21. Arabi YM, Tamim HM, Dhar GS, Al-Dawood A, Al-Sultan M, Sakkijha MH, et al. Permissive underfeeding and intensive insulin therapy in critically ill patients: a randomized controlled trial. Am J Clin Nutr. 2011;93:569-77.

22. Braunschweig CA, Sheean PM, Peterson SJ, Gomez Perez S, Freels S, Lateef $\mathrm{O}$, et al. Intensive nutrition in acute lung injury: a clinical trial (INTACT). JPEN J Parenter Enteral Nutr. 2015;39:13-20.

23. Charles EJ, Petroze RT, Metzger R, Hranjec T, Rosenberger LH, Riccio LM, et al. Hypocaloric compared with eucaloric nutritional support and its effect 
on infection rates in a surgical intensive care unit: a randomized controlled trial. Am J Clin Nutr. 2014;100:1337-43.

24. Desachy A, Clavel M, Vuagnat A, Normand S, Gissot V, Francois B. Initial efficacy and tolerability of early enteral nutrition with immediate or gradual introduction in intubated patients. Intensive Care Med. 2008;34:1054-9.

25. Peake SL, Davies AR, Deane AM, Lange K, Moran JL, O'Connor SN, et al. Use of a concentrated enteral nutrition solution to increase calorie delivery to critically ill patients: a randomized, double-blind, clinical trial. Am J Clin Nutr. 2014; 100:616-25

26. Rice TW, Mogan S, Hays MA, Bernard GR, Jensen GL, Wheeler AP. Randomized trial of initial trophic versus full-energy enteral nutrition in mechanically ventilated patients with acute respiratory failure. Crit Care Med. 2011:39:967-74.

27. National Heart, Lung, and Blood Institute Acute Respiratory Distress Syndrome (ARDS) Clinical Trials Network, Rice TW, Wheeler AP, Thompson BT, Steingrub J, Hite RD, et al. Initial trophic vs full enteral feeding in patients with acute lung injury: the EDEN randomized trial. JAMA. 2012;307:795-803.

28. Taylor SJ, Fettes SB, Jewkes C, Nelson RJ. Prospective, randomized, controlled trial to determine the effect of early enhanced enteral nutrition on clinical outcome in mechanically ventilated patients suffering head injury. Crit Care Med. 1999;27:2525-31.

29. Casaer MP, Van den Berghe G. Nutrition in the acute phase of critical illness. N Engl J Med. 2014;370:2450-1.

30. Heidegger CP, Berger MM, Graf S, Zingg W, Darmon P, Costanza MC, et al. Optimisation of energy provision with supplemental parenteral nutrition in critically ill patients: a randomised controlled clinical trial. Lancet. 2013:381:385-93.

31. Casaer MP, Mesotten D, Hermans G, Wouters PJ, Schetz M, Meyfroidt G, et al. Early versus late parenteral nutrition in critically ill adults. N Engl J Med. 2011;365:506-17.

32. Doig GS, Simpson F, Sweetman EA, Finfer SR, Cooper DJ, Heighes PT, et al. Early parenteral nutrition in critically ill patients with short-term relative contraindications to early enteral nutrition: a randomized controlled trial. JAMA. 2013;309:2130-8.

33. Owais AE, Kabir SI, McNaught C, Gatt M, MacFie J. A single-blinded randomised clinical trial of permissive underfeeding in patients requiring parenteral nutrition. Clin Nutr. 2014;33:997-1001.

34. Casaer MP, Wilmer A, Hermans G, Wouters PJ, Mesotten D, Van den Berghe $\mathrm{G}$. Role of disease and macronutrient dose in the randomized controlled EPaNIC trial: a post hoc analysis. Am J Respir Crit Care Med. 2013;187:247-55.

35. Alberda C, Gramlich L, Jones N, Jeejeebhoy K, Day AG, Dhaliwal R, et al. The relationship between nutritional intake and clinical outcomes in critically ill patients: results of an international multicenter observational study. Intensive Care Med. 2009;35:1728-37.

36. Arabi YM, Haddad SH, Tamim HM, Rishu AH, Sakkijha MH, Kahoul SH, et al. Near-target caloric intake in critically ill medical-surgical patients is associated with adverse outcomes. JPEN J Parenter Enteral Nutr. 2010;34:280-8.

37. Martin CM, Doig GS, Heyland DK, Morrison T, Sibbald WJ, Southwestern Ontario Critical Care Research Network. Multicentre, cluster-randomized clinical trial of algorithms for critical-care enteral and parenteral therapy (ACCEPT). CMAJ. 2004;170:197-204.

38. Weijs PJ, Stapel SN, de Groot SD, Driessen RH, de Jong E, Girbes AR, et al. Optimal protein and energy nutrition decreases mortality in mechanically ventilated, critically ill patients: a prospective observational cohort study. JPEN J Parenter Enteral Nutr. 2012;36:60-8.

39. Allingstrup MJ, Esmailzadeh N, Wilkens Knudsen A, Espersen K, Hartvig Jensen T, Wiis J, et al. Provision of protein and energy in relation to measured requirements in intensive care patients. Clin Nutr. 2012;31:462-8.

\section{Submit your next manuscript to BioMed Central and take full advantage of:}

- Convenient online submission

- Thorough peer review

- No space constraints or color figure charges

- Immediate publication on acceptance

- Inclusion in PubMed, CAS, Scopus and Google Scholar

- Research which is freely available for redistribution

Submit your manuscript at www.biomedcentral.com/submit 